\title{
Research gaps and Health Technology Assessment
}

Leela Barham ${ }^{1}$

1 Independent health economist

\section{INTRODUCTION}

Health Technology Assessment has been defined as «a multidisciplinary process that summarises information about the medical, social, economic and ethical issues related to the use of a health technology in a systematic, transparent, unbiased, robust manner. Its aim is to inform the formulation of safe, effective, health policies that are patient focused and seek to achieve best value» [1].

The primary use of HTA is to provide highquality information to inform stakeholders on the benefits, harms and costs (where this is considered within the scope of the HTA) of health technologies [2].

\section{HTA AND RESEARCH}

EUnetHTA highlights that HTA informs policy but «must always be firmly rooted in research and the scientific method» [1]. Available research is therefore a building block for being able to conduct HTA. In 2009, Eddy argues that HTA has four main stages, and the first is a "systematic evaluation of evidence for a technology and a requirement of good evidence for such things as coverage, placement on formularies and affirmative guidelines» [3].

However, there are gaps in the relevant research base to inform real life decisions on what to invest in, and what to disinvest from.

\section{HTA HELPS TO IDENTIFY RESEARCH GAPS}

Conducting a HTA has a very useful byproduct: the identification of gaps in the evidence base. In 2008, Scott et al. argued that HTAs were an unexploited source of information to inform research [4]. In 2012, Tunis and Turkelson highlighted how this by-product of HTA was being seen as increasingly important role of HTA [2]. They also highlight that HTA can inform understanding of where there is a lack of quantity and/or quality research, methodological limitations in the existing research and the new research designs that could overcome these limitations as well as the need for new methodological research.

In the UK, HTA outputs can explicitly include recommendations for research. The National Institute for Health and Care Excellence (NICE) can recommend use 'Only in Research' (OiR). This restricts use of a technology to research such as a clinical trial [5]. NICE recommendations can also be characterized as Approval with Research (AWR) recommendations where further research is recommended alongside routine use [6]. Up to March 2014, five per cent of NICE recommendations from Technology Appraisals have been OiR recommendations [7]. NICE also has a database of research recommendations from across their wider program of work including clinical guidelines [8]. This database now holds 1,365 research recommendations relating to NICE guidance published between Jun 2006 to February 2014. Two hundred and eleven of these relate to Technology Appraisals. The database includes research questions themselves, such as "What are the long-term recurrence rates of fibroids after uterine artery embolisation or myometomy?" [9] or includes recommendations for specific research including randomized controlled trials (as recommended for parent training/conduct programmes [10]) or registries (as recommend for patients prescribed efalizumab and etanercept [11]).

In Sweden, the HTA agency SBU, is tasked to identify those health technologies whose effects have not been sufficiently assessed [12]. They do this by identifying where there is scientific uncertainty; defined as when systematic literature reviews real that a health technology has uncertain medical effects or where systematic literature reviews are not available. SBU has a database of these uncertainties and the health technologies that they relate to.

In the US, the Agency for Healthcare Research and Quality (AHRQ) has a structured process
Corresponding author Leela Barham leels@btinternet.com

\section{Disclosure}

No funding was provided for this article. The author is an independent consultant who has received funding in the past from the pharmaceutical industry and health care organisations. 
to determined future research needs from recently completed systematic reviews [2].

However not all HTA agencies will systematically consider research gaps and/or set out research recommendations as part of their work [13].

\section{BUT ARE THE GAPS BEING FILLED?}

HTA agencies often may not be able to directly influence research because they are not commissioners of research nor hold research budgets. However, what they say in terms of research gaps or when they recommend use only in research settings, may increase the chance that research takes place then in the absence of HTA reports. Perhaps they are more likely to have greater influence with public funders than private funders. Private funders, like commercial companies manufacturing technologies including devices or pharmaceuticals will need to consider the costs and benefits of filling research gaps (such as the value of providing additional evidence that may alter a HTA recommendation in a given country). They will also need to consider this in light of demands for evidence which may differ by jurisdiction.

There is some evidence that research recommendations are being acted upon. For example, NICE research recommendations are used by others including the National Institute for Health Research, as a public funder of research, and their Health Technology Assessment Programme to commission research [14].
There is evidence that when NICE recommendations are reviewed that new research has been conducted which has helped to fill evidence gaps. But there remain gaps [15]. However, it is currently difficult to determine from the NICE database which research recommendations are of high priority and whether these are systematically acted on.

Proactive efforts are being made though to fill the identified gaps, for example, SBU tries to initiate research that is needed working with the Swedish Research Council [12].

The AHRQ has continued their work on identifying gaps and through their Closing the Gap: revisiting the State of the Science hope that research funders will draw on them to set funding priorities [16].

\section{MAXIMISING THE VALUE OF HTAS AND MAKING MORE INFORMED DECISIONS IN THE FUTURE}

With increasing interest in HTA, and more resources being spent on HTA itself, there should be focus on achieving the best value for money from those HTAs. That should relate not just to implementation of HTA recommendations directly, but also the valuable by-product of identifying research gaps. There are efforts to achieve this but more needs to be done to ensure that research recommendations are acted upon. This will, over time, improve the evidence base and lead to more informed decisions on investment and dis-investment in health care in the future.

\section{REFERENCES}

1. EUnetHTA, Common questions: What is Health Technology Assessment? Available at: http://www.eunethta.eu/ about-us/faq\#t287n73 (last accessed April 2014)

2. Tunis SR, Turkelson C. Using Health Technology Assessment to Identify Gaps in Evidence and Inform Study Design for Comparative Effectiveness Research. J Clin Oncol 2012; 30: 4256-61; http://dx.doi.org/10.1200/ JCO.2012.42.6338

3. Eddy, D Health Technology Assessment and Evidence-Based Medicine: What Are We Talking About? Value Health 2009; 12 Suppl 2: S6-7; http://dx.doi.org/10.1111/j.1524-4733.2009.00551.x

4. Scott NA, Moga C, Harstall C, et al. Using Health Technology Assessment to Identify Research Gaps: An Unexploited Resource for Increasing the Value of Clinical Research. Healthc Policy 2008; 3: e109-27

5. NICE. Technology Appraisal Recommendation Categories. Available at: http://www.nice.org.uk/newsroom/nicestatistics/TADecisionsRecommendationCategories.jsp (last accessed April 2014)

6. Longworth L, Youn J, Bojke L, et al. When Does NICE Recommend the Use of Health Technologies Within a Programme of Evidence Development? A Systematic Review of NICE Guidance. Pharmacoeconomics 2013; 31: 137-49; http://dx.doi.org/10.1007/s40273-012-0013-6

7. NICE. Technology appraisal recommendation summary. Available at: http://www.nice.org.uk/newsroom/nicestatistics/TADecisionsRecommendationSummary.jsp (last accessed April 2014) 
8. NICE. Search research recommendations. Available at: http://www.nice.org.uk/research/index.jsp?action=rrsearch (last accessed April 2014)

9. NICE. Recommendation ID CG 44/3. Available at: http://www.nice.org.uk/research/index.jsp?action=research\&o=703 (last accessed April 2014)

10. NICE. Recommendation IDTA 102/3. Available at: http://www.nice.org.uk/research/index.jsp?action=research\&o=1852 (last accessed April 2014)

11. NICE. Recommendation IDTA 103/1. Available at: http://www.nice.org.uk/research/index.jsp?action=research\&o=1896 (last accessed April 2014)

12. SBU. Scientific Uncertainties - Insufficiently Assessed Health Technologies. December 2012. Available at: http:// www.sbu.se/upload/Kunskapsluckor/Scientific_Uncertainties.pdf (last accessed April 2014)

13. Scott A, Moga C, Harstall C. Using HTA to Identify Research Gaps: A Pilot Study. 2006. HTA Initiative \#24. Available at http://www.ihe.ca/documents/HTA\%20Initiative24.pdf (last accessed April 2014)

14. National Institute for Health Research. Identifying research questions. Available at: http://www.nets.nihr.ac.uk/ identifying-research (last accessed April 2014)

15. Claxton K, Palmer S, Longworth L, et al. Informing a decision framework for when NICE should recommend the use of health technologies only in the context of an appropriately designed programme of evidence development. Health Technol Assess 2012; 16: 1-323; http://dx.doi.org/10.3310/hta16460

16. AHRQ. Series Overview: Closing the Quality Gap: Revisiting the State of Science. Available at: http://www.ahrq. gov/research/findings/evidence-based-reports/er208-overview.html (last accessed April 2014) 